\title{
Possibilities, limits and particularities of plastic surgery treatment in HIV-associated lipodystrophy
}

\author{
Dana Jianu ${ }^{1,2^{*}}$, Anca Streinu-Cercel ${ }^{2,3}$, Maria Filipescu $^{1}$, Ștefan Jianu ${ }^{1}$, Mihaela Vartic$^{1}$, Oltjon Cobani ${ }^{1}$, \\ Adrian Streinu-Cercel ${ }^{2,3}$ \\ From The 10th Edition of the Scientific Days of the National Institute for Infectious Diseases "Prof Dr Matei Bals" \\ Bucharest, Romania. 15-17 October 2014
}

\section{Background}

Given the particularities of the Romanian HIV cohort, an important number of patients have received treatment with first-generation antiretroviral drugs and have developed an associated lipodystrophy. Nowadays HIV-infected patients can benefit from less invasive surgical treatments for lipodystrophy, to ameliorate their psychosomatic status.

\section{Case report}

We present 2 cases of patients with HIV-associated lipodystrophy. These patients underwent specific modern "closed" plastic surgery corrections: liposuction and liporedistribution. The patients were evaluated with a followup of 10 years (the first case) and respectively 6 months (the second case). In each case the possibilities and limits of these treatments were evaluated.

\section{Conclusion}

Treatment of HIV infection should be effective but it should also lead to an improvement in the quality of life. A multidisciplinary approach - infectious diseases physicians, plastic surgeons, anesthesiologists, histopathologists, psychologists etc. - can contribute to a psychosomatic improvement.

\section{Authors' details}

${ }^{1}$ Proestetica Medical Center, Bucharest, Romania. ${ }^{2}$ Carol Davila University of Medicine and Pharmacy, Bucharest, Romania. ${ }^{3}$ National Institute for Infectious Diseases "Prof. Dr. Matei Balş", Bucharest, Romania.
Published: 15 October 2014

doi:10.1186/1471-2334-14-S7-037

Cite this article as: Jianu et al:: Possibilities, limits and particularities of plastic surgery treatment in HIV-associated lipodystrophy. BMC Infectious Diseases 2014 14(Suppl 7):037.

*Correspondence: djianu02@gmail.com

${ }^{1}$ Proestetica Medical Center, Bucharest, Romania

Full list of author information is available at the end of the article

Submit your next manuscript to BioMed Central and take full advantage of:

- Convenient online submission

- Thorough peer review

- No space constraints or color figure charges

- Immediate publication on acceptance

- Inclusion in PubMed, CAS, Scopus and Google Scholar

- Research which is freely available for redistribution
() Biomed Central
C Biomed Central

(c) 2014 Jianu et al; licensee BioMed Central Ltd. This is an Open Access article distributed under the terms of the Creative Commons Attribution License (http://creativecommons.org/licenses/by/4.0), which permits unrestricted use, distribution, and reproduction in any medium, provided the original work is properly cited. The Creative Commons Public Domain Dedication waiver (http:// creativecommons.org/publicdomain/zero/1.0/) applies to the data made available in this article, unless otherwise stated. 